\title{
PESAN SIMBOLIK TRADISI SANDINGAN PADA MASYARAKAT PANDALUNGAN DI DESA JENGGRONG KECAMATAN RANUYOSO KABUPATEN LUMAJANG
}

\author{
Bambang Subahri \\ Institut Agama Islam Syarifuddin Lumajang \\ Email : bambang.subahri@gmail.com
}

\begin{abstract}
ABSTRAK
The tradition of Sandingan carried out from generation to generation by Pandalungan society is a combination of Javanese and Madurese Islamic culture which accomplishes symbolic message for the balance of macrocosm and microcosm which covers relation among human beings, humans and nature, and humans and the creators. This ritual is served by providing food and beverages on Monday, Thursday and Friday evenings started by burning incense and closed by reciting prayers aimed at the spirits of the ancestors.
\end{abstract}

Keywords: Symbolic Message, Tradition, Sandingan and Pandalungan

\section{PENDAHULUAN}

Masyarakat tapal kuda dengan perpaduan tradisi Jawa-Madura kerab disebut dengan masyarakat pandalunganyang kaya dengan tradsi Islam lokalnya. ${ }^{1}$ Suku Jawa dan Madura memiliki banyak keunikan-keunikan yang jarang ditemui pada suku-suku yang lain. ${ }^{2}$ Keunikan ini dikarenakan karakteristik dari kebudayaan Jawa-Madura atau budaya pandalungan ini lebih condong bersifat dekonstruktif, yaitu memperbarui budaya lama dan mengkonstruk ulang dengan budaya-budaya baru yang khas tanpa meninggalkan budaya lama.

Keagamaan masyarakat pandalungan dengan sifat sinkretisnya banyak melahirkan keunikan tersendiri.Dalam hal ini, alam pikiran masyarakat lokal pada umumnya dirumuskan oleh kehidupan manusia yang berada dalam kosmos yaitu

\footnotetext{
${ }^{1}$ Masyarakatpandalungan adalah masyarakat hibrida akibat terjadinya percampuran dua budaya dominan yaitu budaya Jawa dan budaya Madura. Pada umumnya masyarakat pandalungan bertempat tinggal di daerah pedesaan mulai dari pesisir pantai hingga pegunungan, lihat: Ayu Sutarto, "Sekilas tentang Masyarakat Pandalungan" Makalah disampaikan pada acara pembekalan Jelajah Budaya 2006 yang diselenggarakan oleh Balai Kajian Sejarah dan Nilai Tradisional Yogyakarta, tanggal 7-10 Agustus 2006.

${ }^{2}$ Agus. Mengenal Adat Tradisi Sandingan dalam Masyarakat Jawa di Lumajang.(Detik.com, 2017). Dari: http://detikone.com/berita-mengenal-adat-tradisi-sandingan--dalam-masyarakat-jawa-dilumajang.html.
} 
makrokosmos dan mikrokosmos.Makrokosmos dalam pandangan masyarakat dalah sikap dan pandangan hidup terhadap alam semesta yang mengandung kekuatan supranatural dan penuh dengan hal-hal yang bersifat misterius dan ruhaniah.Sedangkan mikrokosmos dalam pandangan masyarakat adalah sikap dan acuan hidup terhadap dunia nyata yang tercermin dalam kehidupan manusia dan lingkungannya, susunan kemasyarakatan, tata kehidupan manusia sehari-hari dan segala sesuatu yang nampak oleh mata. ${ }^{3}$

Selain itu, masyarakat masyarakat pandalungan percaya pada adanya rohroh atau arwah leluhur serta makhluk-makhluk halus lainnya yang menempati alam semesta sekitar tempat tinggal mereka. ${ }^{4}$ Roh-roh ini dipercaya dapat mendatangkan keselamatan, kebahagiaan, keberuntungan atau bahkan pula membawa petaka bagi manusia. Untuk itu, agar orang tersebut ingin mendapatkan keselamatan dan lain-lain maka ia harus berbuat sesuatu untuk mempengaruhi alam semesta seperti dengan mengadakan upacara-upacara ritual yang dikenal dengan istilah slametan. ${ }^{5}$

Slametan kerapkali dilakukan oleh masyarakat pandalungan untuk mencapai tujuan yang diharapkan.Hal ini untuk menjaga keseimbangan antara alam makrokosmos dan mikrokosmos.Kebiasaan-kebiasaan yang dilakukan oleh masyarakat pandalunganyang sampai sekarang menjadi tradisi yang melekat dan mendarah daging memunculkan sebuah ritus/ritual yang diyakini dan dipatuhi.Salah satu macam dari ritual slametan yang sampai sekarang masih diyakini dan dipatuhi oleh masyarakat pandalungan di desa Jenggrong kecamatan Ranuyoso kabupaten Lumajang yaitu sandingan malam Jum'at, malam Senin dan malam Kamis.Selanjutnya, yang dimaksud sandinganadalah sebutan untuk sesaji

${ }^{3}$ Munawir Haris. Spiritualitas Islam dalam Trilogi Kosmos. Jurnal Ulumuna IAIN Mataram. DOI: http://dx.doi.org/10.20414/ujis.v17i2.165. Vol 17, No 2 (2013).

${ }^{4}$ Ibid.

5 Clifford Geertz.Abangan, Santri, Priyayi dalam Masyarakat Jawa. terj. Aswab Mahasin.(Bandung: Dunia Pustaka Jaya, 1981). 1-5. 
atau sesajen yang diperuntukkan bagi para leluhur yang telah mendahului berupa makanan dan minuman yang disukai leluhur diwaktu masa hidupnya. ${ }^{6}$

Menurut George Herbert Mead yang menerangkan bahwa manusia dalam berinteraksi dengan orang lain menggunakan bahasa sebagai salah satu simbol signifikan. Dalam hal ini, simbol dibagi menjadi mind, self dan society.Pemaknaan atas simbol yang dalam hal ini adalah sandinganyang dilakukan pada malam tertentu tersebut dipengaruhi oleh diri (self) dari orang tersebut, yang mana konsepnya "l" dan "Me". Hal ini yang memunculkan berbagai macam makna yang berbeda dari tiap-tiap orang dalam memaknai sandingan malam Jum'at, Senin dan Kamis. ${ }^{7}$

Lebih lanjut, bentuk sandingan yang dilakukan malam Jum'at, malam Senin dan malam Kamis lebih bersifat simbolis dalam penghormatan atas leluhur yang mendahului berupa makanan atau minuman yang disukai dan disuguhkan pada waktu menjelang magrib dengan didahului membakar kemenyan. ${ }^{8}$ Berangkat dari permasalah inipenulis mengambil fokus penelitiantentang tentang pesan simboliksandinganyang khas masyarakat pandalungan yang berbeda dengan tradisi Jawa maupun Madura.

\section{METODE}

Penelitianmenggunakan pendekatan kualitatif yang dilakukan di desa Jenggrong Kecamatan Ranuyoso Kabupaten Lumajang. ${ }^{9}$ Masyarakat di Desa

\footnotetext{
${ }^{6}$ Misalnya orang tua, kakek nenek buyut dan sebagainya.Dalam tradisi Jawa, masih banyak masyarakat modern yang memberikan sandingan di malam tertentu.Banyak yang percaya jika di malam-malam tertentu, para leluhur yang telah meninggal pulang ke rumah.Maka dari itu mereka sengaja memberi sesaji berupa makanan kesukaan nenek moyang mereka agar mereka bisa makan saat pulang.Nikmatus Solikha. 5 Tradisi Jawa Ini Masih Dilaksanakan Masyarakat Modern. (Orangdalam.com, 2016). Diakses dari: http://www.orangdalam.com/tradisi-keliru-masyarakat/2681.

7 George H.Mead dalam Agus.Mengenal Adat Tradisi Sandingan dalam Masyarakat Jawa di Lumajang.(Detik.com, 2017).

8 Clifford Geertz.Abangan, Santri, Priyayi dalam Masyarakat Jawa. terj. Aswab Mahasin.(Bandung: Dunia Pustaka Jaya, 1981). 1-5.

9 Nama desa ini berasal dari gabungan kata ajijing dan agrunggung, masing-masing dalam bahasa Madura berarti tertatih-tatih dan menggerutu. Desa ini diberi nama oleh serombongan penjual kayu bakar yang tiba di daerah ini pada akhir abad ke-19, ketika Volume 4, Nomor 2, Agustus 2018| 294
} 
Jenggrong merupakan masyarakatpandalungan, yaitumasyarakat hibrida akibat terjadinya percampuran dua budaya dominan yaitu budaya Jawa dan budaya Madura. ${ }^{10}$ Sementara, pengumpulan data dalam penelitian dilakukan dengan observasi wawancara dan dokumentasi. ${ }^{11}$ Adapun subjek penelitian yang menjadi responden dalam penelitian ini ialahUst. Ahmad Abdul Rumzi, Bapak Nawawi dan H. Munarsum yang merupakan para pemuka agama serta tokoh masayarakt di desa Jenggrong kecamatan Ranuyoso Kabupaten Lumajang.

\section{PEMBAHASAN}

\section{Pesan Simbolik}

Secara etimologi, simbol berasal dari kata kerja Yunani, Sumballaatau sumbaallein yang berarti berwawancara, merenungkan, memperbandingkan, bertemu, melemparkan, menyatukan. Jadi simbol adalah penyatuan oleh bertemu, melemparkan jadi satu, menyatukan. Jadi simbol adalah penyatuan oleh subyek atas dua hal menjadi satu. Sedangkan Reede menyebutkan bahwa simbol berasal dan kata Greekatausunniballo yang berarti "saya bersatu bersamanya”, "penyatuan bersama”. Pemahaman yang diberikan oleh Reede ini tidak jauh berbeda dengan pemahaman sebelumnya. ${ }^{12}$

Pemahaman kita tentang simbol ini harus kita bedakan dengan pemahaman terhadap tanda (sign). Tanda adalah formula makna fisik yang cenderung sebagai operator, sedangkan simbol adalah formula makna yang berfungsi sebagai designator sebagaimana yang diungkapkan oleh Cassier

mereka susah-payah membawa barang dagangannya tersebut melalui desa yang sudah dibuka sejak 2 generasi sebelumnya. Secara luas wilayah, desa ini Luas: 19,3 km², Jumlah penduduk $\quad 6.008$ jiwa dengan jumlah kepadatan penduduk mencapai 311 jiwa tiap-tiap $\mathrm{km}^{2}$. Diakses dari: https://id.wikipedia.org/wiki/Jenggrong, Ranuyoso, Lumajang

${ }^{10}$ Ayu Sutarto, "Sekilas tentang Masyarakat Pandalungan," Makalah disampaikan pada acara pembekalan Jelajah Budaya 2006 yang diselenggarakan oleh Balai Kajian Sejarah dan Nilai Tradisional Yogyakarta, tanggal 7-10 Agustus 2006.

${ }^{11}$ Uhar Suharsaputra. Metode Penelitian Kuantitatif, Kualitatif, dan Tindakan, (Bandung: Refika Aditama. 2012), 209. Lihat juga: Sugiyono. Metode Penelitian Pendidikan Pendekatan Kuantitatif, Kualitatif, dan R\&D. (Bandung: Alfabeta, 2010). 194.

12 Puspitasari Rakhmat, Jeanny Maria Fatimah, Makna Pesan Simbolik Non Verbal Tradisi Mappadendang di Kabupaten Pinrang, Jurnal Komunikasi KAREBA. Ilmu Komunikasi Fakultas Ilmu Sosial dan Ilmu Politik Universitas Hasanuddin. Vol. 5 No.2 Juli - Desember 2016. 
berikut, "simbol bila diartikan tepat tidak dapat dijabarkan menjadi tanda sematamata. Tanda dan simbol masing-masing terletak pada dua bidang permasalahan yang berlainan : tanda adalah bagian dan dunia fisik; simbol adalah bagian dan dunia maknamanusia. Tanda adalah "operator", simbol adalah “designator".Tanda, bahkan pun bila dipahami dan digunakan seperti itu, bagaimana pun merupakan sesuatu yangfisik dan sunstansial; simbol hanya memiliki nilai fungsional.Sependapat dengan Cassier, Carl Gustav Jung psikiater Swissjuga membedakan antara tannda (zeichen) dan simbol.Jung mengatakan bahwa antara pemakaian sesuatu sebagai tanda (symbolic). Simbol mengandaikan bahwa ekspresi yang terpilih adalah formulasi yang paling baik akan sesuatu yang relative tidak terkenal, namun hal itu diketahui sebagai hal yang ada atau diharapkan ada. ${ }^{13}$

Selama suatu simbol hidup, simbol itu adalah ekspresi suatu hal yang tidak dapat ditandai dengan tanda yang lebih tepat.Simbol hanya hidup selama simbol mengandung makna bagi kelompok besar manusia, sebagai sesuatu yang mengandung milik bersama sehingga simbol menjadi social yang hidup dan pengaruhnya menghidupkan. Manakala makna telah lahir dan suatu simbol, yakni ketika diperooleh ekspresi yang dapat merumuskan hal yang dicari dengan lebih tepat dan lebih baik, matilah simbol itu dan simbol hanya mempunyai makna historis.

Simbol yang hidup mengungkapkan hal yang tidak terkatakan dalam cara yang tidak teratasi. Semua makna budaya diciptakan dengan menggunakan simbolsimbol.Simbol itu sendiri meliputi apapun yang kita rasakan atau kita alami.pada dasarnya simbol dapat dibedakan menjadi:

a. Simbol-simbol universal, berkaitan dengan arti pos, misalnya tidur sebagai lambang kematian.

b. Simbol cultural yang dilatarbelakangi oleh suatu kebudayaan tertentu misalnya badik dalam kebudayaan Sulawesi selatan.

${ }^{13}$ Ibid. 
c. Simbol individual yang biasanya daoat ditafsirkan dalam konteks keseluruhan karya seorang pengarang. ${ }^{14}$

\section{Tradisi}

Tradisi adalah kesamaan benda material dan gagasan yang berasal dari masa lalu namun masih ada hingga kini dan belum dihancurkan atau dirusak.Tradisi dapat di artikan sebagai warisan yang benar atau warisan masa lalu.Namun demikian tradisi yang terjadi berulang-ulang bukanlah dilakukan secara kebetulan ataudisengaja. ${ }^{15}$ Selanjutnya, tradisi dapat dirubah diangkat, ditolak dan dipadukan dengan aneka ragam perbuatan manusia. ${ }^{16}$

Selanjutnya, tradisi adalah sesuatu yang dilakukan secara turun menurun dan sudah menjadi kebiasaan dari orang-orang terdahulu. ${ }^{17}$ Lebih khusus tradisi yang dapat melahirkan kebudayaan masyarakat dapat diketahui dari wujud tradisi itu sendiri. Menurut Koentjaraningrat, kebudayaan itu mempunyai paling sedikit tiga wujud, yaitu: a) Wujud Kebudayaan sebagai suatu kompleks ide-ide, gagasangagasan, nilai-nilai, norma-norma, peraturan, dan sebagainya. b) Wujud kebudayaan sebagai kompleks aktivitas kelakuan berpola dari manusia dalam masyarakat. c) Wujud kebudayaan sebagai bendabenda hasil karya manusia. ${ }^{18}$

Dalam sistem keyakinan mereka bahwa pemberian kuatan gaib harus berbeda dengan pemberian terhadap yang lain. Jadi mereka tidak asal memberi tetapi berangkat dari sistem kognitif yang telah di peroleh dari para pendahulunya. ${ }^{19}$

Seiring berjalannya waktu, tradisi yang masih berbau hindu dan Budha tersebut mengalami perubahan-perubahan dalam pelaksanaannya yang

\footnotetext{
14 Puspitasari Rakhmat, Jeanny Maria Fatimah, Makna Pesan Simbolik Non Verbal Tradisi Mappadendang di Kabupaten Pinrang, Jurnal Komunikasi KAREBA. Ilmu Komunikasi Fakultas Ilmu Sosial dan Ilmu Politik Universitas Hasanuddin. Vol. 5 No.2 Juli - Desember 2016.

${ }^{15}$ Piotr Sztompka, Sosiologi Perubahan Sosial, (Jakarta: Prenada Media Grup, 2007). 69.

${ }^{16}$ C.A. Van Peursen, Strategi Kebudayaan. (Yogyakarta: Kanisisus, 1988). 11.

${ }^{17}$ Dr. Nur Syam, Islam Pesisir (Yogyakarta: PT. LkiS Pelangi Aksara, 2005). 166

${ }^{18}$ Mattulada, Kebudayaan Kemanusiaan Dan Lingkungan Hidup, (Hasanuddin University Press, 1997), Hal. 1

${ }^{19}$ Ibid. 245-247
} 
dipelopori oleh Wali Songo. Salah satunya yang mengalami perubahan adalah tradisi manganan kuburan menjadi tradisi Islam lokal (khaul). Tradisi manganan kuburan mengandung makna mendekatkan hubungan antara dunia kemanusiaan dalam kosmos yang terbatas dengan dunia alam kubur dalam kosmos yang tidak terbatas. ${ }^{20}$ Makam, dengan demikian mengandung mitologi dan mistifikasi. Mitologi dan mistifikasi itu tidak datang dengan sendiriya akan tetapi melalui proses pelembagaan dan habitualisasi. Untuk melestarikan mitos-mitos itu, digunakanlah berbagai sarana dan instrumen yang mendukung yaitu pengajian, tahlilan, yasinan dan berbagai upacara yang bermuatan religius. ${ }^{21}$

\section{Sandingan}

Berdasarkan data lapangan tentang definisi sandingan yang sulit ditemukan di pembendaharaan ilmiah sandingan ialah tradisi sesaji yang diperuntukkan bagi para leluhur yang telah mendahului dengan tujuan memberikan sanyanjungan bagipara leluhur guna dijadikan uswah bagi para keturunannya. Misalnya sanak saudara, orang tua, kakek, nenek, buyut dan sebagainya. ${ }^{22}$ Di desa Jenggrong tradisi sandingan biasa dilakukan pada tiga malam yang dianggap sakral yaitu malam Senin, malam Kamis dan malam Jum'at.

Warga Desa Jenggong meyakini dengan tradisi sandinganakan membuat para leluhur yang telah meninggal pulang ke rumah. Dan akan membuat arwah orang yang meninggal menjadi tenang dan tidak mengganggu orang yang masih hidup.Maka dari itu setiap orang yang sudah meninggal harus diadakannya sandingan.Jika tidak, maka arwah orang meninggal akan nyanding (datang kepada orang yang masih hidup) misalkan dengan menghantui anak kecil, agar si orang tua mencari tahu menyebab anaknya tersebut sering menangis. Maka dari itu terkadang banyak arwah

\footnotetext{
${ }^{20} \mathrm{Ibid}, 243$

${ }^{21}$ Ibid, 249

${ }^{22}$ Wawancara. Bapak H. Nawawi di Kediaman, dusun Lumapang Gemuling RT: 09 RW: 29 desa Jenggrong Kecamatan Ranuyoso Kabupaten Lumajang. 12-06-18. 
yang menuntutuntuk disandingi. Dengan kejadian yang sering dialami tersebut banyak masyarakat Jenggrong sengaja memberi sesaji berupa makanan kesukaan nenek moyang mereka, agar mereka bisa makan saat pulang. Sesuai yang dikatakan oleh Haji Munarsum, salah satu masyarakat yang masih melakukan tradisi sandingan:

"Sandingan ruah elakonin makle se odik tak paddheng ke se ekobur makle she ekobur mun mule kah bengkonah tak leng ngaleng, mangkannah nambuh sandingin. Mon tak esandingin, reng mateh ruoh minta. Pas cellok sambih Kudhu khususagi ke seng esandingin, makle depak ke oreng se esandingin ben oreng se neng koburen ruah tak rebuk'en". ${ }^{23}$

Tradisisandingan ini sudah berjalan sangat lama dan turun-menurun. Jika dahulu sandingan masih bercampur dengan budaya Hindu Budha yang masih menganut faham animisme dan dinamisme, maka sekarang tradisi sandingan telah bertransformasi menjadi tradisi yang bernafaskan Islam. Makanan yang disajikan pada waktu sandingan akan digunakan untuk sedekah ataupun dimakan sendiri oleh orang yang melaksanakannya setelah di khususkan atau didoakan kepada arwah yang dimaksud.

Hal tersebut tentu saja tidak melanggar syari'at yang telah ditetapkan. Karena sejatinya makanan yang disajikan saat sandingan hanyalah pelengkap dari do'a-do'a yang dipanjatkan bagi orang yang sudah meninggal. Maka hakikat dari sandingan itu sendiri adalah do'a-do'a maupun sholawat yang dipanjatkan untuk ketenangan orang yang dikubur.

Dalam beberapa pendapat sandingandiperbolehkan dalam Islam selama tidak melanggar syari'at yang berlaku. Makanan yang dikeluarkan ketika sandingan tidak ditentukan, masyarakat menyajikan makanan seadanya dan yang dianggap mampu sesuai dengan keikhlasan orang yang melakukan sandingan tersebut. Sandingan itu dijadikan amal sedekah bagi orang yang meninggal agar tetap tenang di alam kubur. Karena orang yang meninggal itu

${ }^{23}$ Wawancara. H. Munarsum di Kediaman. 12-06-18. 
ibarat orang yang tenggelam di laut dan membutuhkan pertolongan orang yang berada di daratan. ${ }^{24}$

\section{Pandalungan}

Masyarakat pandalungan adalah masyarakat hibrida akibat terjadinya percampuran dua budaya dominan yaitu budaya Jawa dan budaya Madura. Pada umumnya masyarakat pandalungan bertempat tinggal di daerah pedesaan mulai dari pesisir pantai hingga pegunungan. ${ }^{25}$

Masyarakat pandalungan kerap juga disebut masyarakat multiakulturatif yang telah menarik perhatian banyak kalangan peneliti untuk mengkaji ulang tradisi Islam Jawa masyarakat pandalungan. Disebut multiakulturasi karena proses bercampurnya budaya Madura dan Jawa dari sisi bahasa dan seni-budaya juga di ikuti dengan bercampurnya budaya keagamaan yang menghasilkan budaya keagamaan yang unik dan tidak dapat di jumpai di daerah Jawa dan Madura secara etnografis. ${ }^{26}$

Rekonstruksi sejarah membuktikan bahwa masyarakat pandalungan bermula dari kabupaten Lumajang yang kemudian tersebar di seluruh wilayah Tapal Kuda. ${ }^{27}$ Lumajang dalam tiga tahun terakhir juga diklaim sebagai kerajaan Islam tertua di Jawa yang dipimpin Arya Wiraraja yang mulanya adalah adipati Sumenep yang kemudian diberi hadiah berupa wilayah kerajaan Majapahit bagian timur oleh raja Majapahit pertama karena jasanya yang sangat besar. Kemudian sebagian besar masyarakat Madura melakukan

\footnotetext{
${ }^{24}$ Berdasarkan data Wawancara pada salah seorang Ust. Ahmad Abdul Rumzi yang berasal dari Madura yang mendapat tugas akhir dari pondok pesantren (tugasan) Sidogiri untuk mengamalkan ilmunya di yayasan Nurul Ulum Jenggrong.12-06-18.

${ }^{25}$ Ayu Sutarto, "Sekilas tentang Masyarakat Pandalungan," Makalah disampaikan pada acara pembekalan Jelajah Budaya 2006 yang diselenggarakan oleh Balai Kajian Sejarah dan Nilai Tradisional Yogyakarta, tanggal 7-10 Agustus 2006.

${ }^{26}$ Ayu Sutarto, "Sekilas tentang Masyarakat Pandalungan, 2006.

27 Tapal Kuda adalah nama sebuah daerah di provinsi Jawa Timur, tepatnya di bagian timur provinsi tersebut. Dinamakan Tapal Kuda, karena bentuk kawasan tersebut dalam peta mirip dengan bentuk tapal kuda atau berupa huruf "U". Kawasan Tapal Kuda meliputi Pasuruan (bagian timur), Probolinggo, Situbondo, Bondowoso, Banyuwangi, Jember dan Lumajang lihat: Djoko Soejono, Agus Supriono dan Julian Adam Ridjal, "Faktor Pendorong dan Penghambat Mewujudkan Model Sinergis Pengembangan Wilayah Tapal Kuda Menjadi Kesatuan Daerah Perencanaan di Era Otonomi Daerah," Jurnal UNEJ, (1 Maret 2011), J-SEP Vol. 5 No.
} 
imigrasi dan menempati daerah-daerah di wilayah Tapal Kuda dan Lumajang sebagai pusat kotanya. ${ }^{28}$

\section{Prosesi Tradisi Sandingan di Desa Jenggrong}

Seperti yang sudah dikatakan di atas, tradisi sandingan di Desa Jenggrong dilaksanakan pada tiga malam yang dinggap sakral yakni malam Senin, malam Kamis dan malam Jum'at. Adapun makanan yang disajikan pada tradisi sandingan tersebut tergolong sederhana dan seadanya, yaitu nasi, lauk pauk, seperti telur, ikan, air putih, tehatau kopi juga rokok jika yang meninggal orang laki-laki. Selain itu, warga Jenggrongjuga menggunakan makanan yang disukai orang yang meninggal, seperti bakso, rujak, nasi ketan dan lain sebagainya.

Sandingan tersebut disajikan sebelum maghrib, karna dalam kepercayaaan masyarakat setempat jika lewat dari jam enam sore arwah yang meninggal itu akan pulang ke alamnya. Maka dari itu sandingan itu dilaksanakan sebelum jam enam sore .Setelah makanan tersaji, kemudian membakar dupa (kemenyan) dan membaca surat-surat pendek beserta sholawatyang dikhususkan kepada orang yang meninggal.

Berdasarkan data yang disampaikan H. Nawawi, sandinganmerupakan tradisi menyanjung orang yang sudah meninggal, dan para leluhur yang sudah mendahului. Misalnya kakek, nenek, buyut dan seterusnyadengan cara menaruh makanan lengkap yang kemudian dilanjutkan dengan bacaan sholawatserta do'a yang dipanjatkan dengan tujuan agar di kubur tenang di alam sana dan tidak mengganggu orang yang telah ditinggalkan (nyanding). Membacakan surat-surat pendek tertentu dengan diiringi membakar dupa (minyan) dan memanggil nama-nama orang yang telah meninggal, karna jika tidak dikhususkan maka arwah yang berada didalam kubur itu akan berebutan.Sandingan dilakukanmalam Senin, malam Kamis dan malam Jum'at". ${ }^{29}$

\footnotetext{
${ }^{28}$ Herman Sinung Janutama, Majapahit Kerajaan Islam, (Jakarta: Noura Books Publishing. 2014), 67. Lihat: pula: Agus Sunyoto, Atlas Wali Songo, (Jakarta: IIMAN. 2016). 120-125.

${ }^{29}$ Wawancara. Bapak Nawawi di Kediaman. 12-06-18.
} 


\section{Nilai-nilai di balik Makna simbolik Sandingan}

Sandingan dalam makna yang lebih mendalam pada pasarnya merupakan makna simbolik pesan dakwah yang sifatnya vertikalhorisontal.Menurut Isyantidalam Agusdalam sebuaah tradisi ada nilai yang terkandung di dalamnya yaitu nilai gotong-royong, nilai persatuan dan kesatuan, nilai musyawarah, nilai pengendalian sosial dan nilai kearifan lokal. ${ }^{30}$

Sedangkan penerapan nilai-nilai tersebut dalam tradisi sandingan di Desa Jenggrong, antara lain: pertama, nilai kepedulian, dalam tradisi sandingan tersebut terlihat dalam prosesi yang dilaksanakan dalam tradisi sandingan oleh para masyarakat di kalangan rumah masing-masing yaitu rasa kepeduliannya terhadap leluhur yang sudah meninggal. Tak lazim lagi bahwa di Indonesia tidak banyak yang melakukan tradisi ini sebagai kebiasaan yang turun-temurun dengan tujuan menyanjung orang yang sudah meninggal dan para leluhur yang sudah mendahului.

Kedua, nilai kebaikan yang tercermin ketika sesaji yang diperuntukkan kepada para leluhur kita niatkanuntuk memanjatkan do'a yang ditujukanpada para arwah yang sudah meninggal sebagai bentuk kabaikan yang sangat tidak mungkin jika dilakukan secara langsung kecuali dengan makna pesan simbolik sandingan, karna hanya dengan tradisi ini orang yang masih hidup bisa menjalin komunikasi dengan arwah yang sudah meninggal.

Ketiga, nilai musyawarah yang ditunjukkan dalam tradisi sandinganjika mengundang para tetangga-tetangga dekat untuk ikut serta dalam prosesi tradisi sandingan yaitu akan jauh lebih jika banyak yang mendoakan arwah para leluhur.

Keempat, nilai pengendalian sosial, dalam tradisi sandingan masyarakat memberikan ucapan sekaligus perwujudan rasa syukur kepada sang pencipta dan dengan tradisi sandingan masyarakat mampu untuk mempertahankan dan menjaga tradisi leluhur.

${ }^{30}$ Agus. Mengenal Adat Tradisi Sandingan dalam Masyarakat Jawa di Lumajang. Detik.com: 2017. Diakses dari: http://detikone.com/berita-mengenal-adat-tradisi-sandingan--dalammasyarakat-jawa-di-lumajang.html 
Kelima, nilai kearifan lokal yang ditunjukkan antara lain pada saat masyarakat mampu menyediakan sesaji, membacakan doa-doa atau suratsurat pendek. Sesaji yang disediakan masyarakat memang tergolong sederhana dan seadanya. Dengan demikian tidak hanya yang melakukan tradisi sandingan saja yang menikmati, namun semua masyarakat atau tetangga-tetangga dekat yang di undang dalam prosesi sandingan dan semua golongan dapat menikmati tradisi sandingan.

Tradisi sandingan ini dianggap sebagai media penghubung antara yang masih hidup (manusia) dengan makhluk halus/arwah leluhur mereka.Kepercayaan masyarakat menganggap bahwa di dunia ini tidak hanya dihuni oleh manusia saja, namun juga makhluk-makhluk halus khususnya arwah leluhur dan manusia punya kewajiban untuk menghormatinya.Tradisi sandingan yang dilakukan pada malam-malam tertentu ini merupakan suatu kepercayaan yang dianut oleh masyarakat desa Jenggrong dan sekitarnya yang bertujuan untuk menghormati arwah leluhur yang sudah meninggal dan untuk menjaga keselamatan bagi penganutnya.

\section{KESIMPULAN}

Dari pembahasan di atas dapat disimpulkan, sandingan adalah tradisi mengirim do'a kepada arwah para leluhur dengan sajian berupa makanan seadanya atau makanan yang disukai oleh arwah yang disandingi, seperti nasi, telur dan air minum, rokok jika yang meninggal seorang laki-laki.Dalam Islam sandingan diperbolehkan selama tidak melanggar syari'at Islam.Sandingan sebuah tradisi yang sederhana namun syarat akan makna yang mendalam. Meskipun hanya dengan makanan atau sajian yang serba sederhana, namun sandingan adalah bentuk penghormatan dan wujud nyata kepedulian orang yang masih hidup kepada arwah yang telah meninggal. Kendatipun kita tidak bisa melihat dengan kasat mata arwah yang datang untuk meminta dido'akan, namun kita tahu manusia adalah makhluk sosial yang tidak bisa hidup tanpa orang lain. 
Dalam makna simbolik, sandingan mengandung maknya yang lebih mendalam dengan keseimbangan mikrosmos dan makrosmos antara hubungan manusiadengan manusia, manusia dengan alam dan manusia dengan sang pencipta. Sehingga sandingan yang dilakukan pada malam-malam yang dianggap sakral ini bersifat vertikal dan horisontal melalui media simbolik makanan, minuman dan segala macam yang disukai para leluhur, dengan demikian hal ini tidak dapat diartikan secara empiris-rasionalis melaikan idealogis-metafisis.

\section{REFERENSI}

Agus. Mengenal Adat Tradisi Sandingan dalam Masyarakat Jawa di Lumajang. Detik.com: 2017. Diakses dari: http://detikone.com/berita-mengenal-adat-tradisisandingan--dalam-masyarakat-jawa-di-lumajang.html

Djoko Soejono, Agus Supriono dan Julian Adam Ridjal, "Faktor Pendorong dan Penghambat Mewujudkan Model Sinergis Pengembangan Wilayah Tapal Kuda Menjadi Kesatuan Daerah Perencanaan di Era Otonomi Daerah," Jurnal UNEJ, (1 Maret 2011), J-SEP Vol. 5 No.Geertz, Clifford, Abangan, Santri, Priyayi dalam Masyarakat Jawa, terj. Aswab Mahasin, Bandung: Dunia Pustaka Jaya, 1981.

Geertz, Clifford, Abangan, Santri, Priyayi dalam Masyarakat Jawa, terj. Aswab Mahasin, Bandung: Dunia Pustaka Jaya, 1981.

,Agama Jawa.Depok: Komunitas Bambu. 2014 .

Haris, Munawir. Spiritualitas Islam dalam Trilogi Kosmos. Jurnal Ulumuna IAIN Mataram. DOI: http://dx.doi.org/10.20414/ujis.v17i2.165. Vol 17, No 2 (2013).

Mattulada.Kebudayaan Kemanusiaan dan Lingkungan Hidup, Hasanuddin University Press. 1997.

Puspitasari Rakhmat, Jeanny Maria Fatimah, Makna Pesan Simbolik Non Verbal Tradisi Mappadendang Di Kabupaten Pinrang, Jurnal Komunikasi KAREBA. IImu Komunikasi Fakultas Ilmu Sosial dan Ilmu Politik Universitas Hasanuddin.Vol. 5 No.2 Juli - Desember 2016.

Solikha, Nikmatus. 5 Tradisi Jawa Ini Masih Dilaksanakan Masyarakat Modern.Orangdalam.com: 2016. Diakses dari: http://www.orangdalam.com/tradisi-keliru-masyarakat/2681

Suharsaputra, Uhar. Metode Penelitian Kuantitatif, Kualitatif, dan Tindakan. Bandung: Refika Aditama. 2012.

Sugiyono. Metode Penelitian Pendidikan Pendekatan Kuantitatif, Kualitatif, dan R\&D. Bandung: Alfabeta, 2010. 
Sutarto,Ayu. "Sekilas tentang Masyarakat Pandalungan," Makalah disampaikan pada acara pembekalan Jelajah Budaya 2006 yang diselenggarakan oleh Balai Kajian Sejarah dan Nilai Tradisional Yogyakarta, tanggal 7-10 Agustus 2006.

Syam, Nur. Islam Pesisir. Yogyakarta: PT. LkiS Pelangi Aksara. 2005.

Sztompka,Piotr.Sosiologi Perubahan Sosial. Jakarta: Prenada Media Grup. 2007.

Tim Penulis. Desa Jenggrong. diakses dari: https://id.wikipedia.org/wiki/Jenggrong,_Ranuyoso,_Lumajang

Van Peursen, C.A. Strategi Kebudayaan. Yogyakarta: Kanisisus. 1988. 